\title{
Recycled concrete at early age
}

\author{
E. Rozière, A.Z. Bendimerad, and A. Loukili \\ GeM \\ J.-C. Souche, M. Salgues, and E. Garcia-Diaz \\ C2MA
}

P. Devillers

Ecole Nationale Supérieure d'Architecture de Montpellier

\begin{abstract}
This chapter presents the methodology and results of a comprehensive experimental study about early age behavior of concrete with recycled concrete aggregates (RCA). This study includes the determination of RCA total absorption and absorption rate, the behavior of fresh concrete under standard and severe drying conditions, and the assessment of properties of hardening concrete. The RCA used in this study (provided by RECYBÉTON Project) showed high absorption rate. They reached $90 \%$ of the nominal absorption within the first $2 \mathrm{~h}$, and their absorption was even faster in fresh cement paste. The monitoring of RCA water saturation in cement paste also showed a release of absorbed water when exposed to severe drying. When shifting from standard to severe drying, the increase of evaporation rate did not result in increased shrinkage to mass-loss ratios. However higher shrinkage magnitudes were reached because plastic shrinkage development was accelerated in severe drying conditions thus it could develop before setting. The air entry pressure concept was used to analyze the cracking sensitivity of fresh concrete. It was assessed on various concrete mixtures with and without RCA. A strong correlation was found between air entry pressure and negative capillary pressure at cracking time. The Free water to $\operatorname{Binder}\left(W_{\mathrm{f}} / B\right)$ ratio was found to influence directly
\end{abstract}


the air entry pressure. The $\left(W_{\mathrm{f}} / B\right)$ ratio accounts for the effects of initial water saturation of RCA. The evolution of plastic shrinkage, Young's modulus, and tensile strength were continuously monitored from fresh state to $24 \mathrm{~h}$. The initial water saturation of RCA had limited influence on these properties. Restrained shrinkage tests would be necessary to assess the influence of RCA proportion on cracking sensitivity and estimate relaxation.

\section{I INTRODUCTION}

Shrinkage-induced cracking affects the durability of concrete and concrete structures. This actually favors the ingress of chemically aggressive agents and the corrosion of steel reinforcement. Several phenomena are likely to promote cracking of concrete at an early age. The first one is due to the build-up of negative capillary pressure in fresh cement paste (Radocea 1994; Slowik et al. 2008). Negative capillary pressure can be caused by evaporation when concrete is no longer covered by bleeding and/or curing water. As soon as air entry pressure is reached, cracks are likely to appear. Plastic shrinkage develops when the evaporation rate exceeds the bleeding rate (Wittmann 1976). Thus, the accelerated drying of fresh concrete is likely to increase plastic shrinkage (Turcry and Loukili 2006; Mbemba 2010). The second phenomenon is restrained shrinkage on hardening concrete (see Figure 8.3). Plastic shrinkage cannot freely develop in most of the concrete structures. Moreover, the elastic modulus of concrete starts increasing from very early age, which is likely to induce significant stresses, whereas tensile strength is still relatively low. Therefore, the time period that covers the setting time and early hardening can be considered as critical for cracking (Hammer et al. 2007; Roziere et al. 2015). Recycled concrete aggregates (RCA) are reported to lead to higher shrinkage and creep, and lower strength and elastic modulus, for a given binder content. As a consequence, concrete mixtures are designed to achieve constant slump or strength. However, the studies dealing with early-age behavior are rather scarce. Moreover, RCA are porous aggregates with variable total absorptions and absorption rates; thus, their initial water saturation is likely to have a significant influence on effective water content of cement paste and thus on all concrete properties.

A comprehensive study has been designed in order to characterize RCA and fresh and hardening concrete, from mixing to $24 \mathrm{~h}$. Two laboratories have been involved in this study: Center of materials Mines Alès (C2MA), at Ecole des Mines d'Alès, France, and Civil Engineering and Mechanics Research Institute (GeM), at Ecole Centrale de Nantes, France. Concretes were tested under severe and standard drying conditions, respectively. Severe drying actually promotes the firstly described phenomenon, that is, cracking of the fresh concrete. Two main parameters were investigated: the proportion of RCA aggregates and their initial water saturation.

Firstly, this chapter gives a description of phenomena causing cracking of concrete at the early age and related experimental results in the state-of-the-art part. Then, the two-part testing program is presented. The experimental results and discussions include evaporation rates, plastic shrinkage magnitudes, and cracking sensitivity. They first deal with the behavior of fresh concrete and then with hardening concrete.

\subsection{STATE OF THE ART}

The study presented in this chapter mainly deals with plastic shrinkage and cracking of concrete with RCA at the early age. The results available in the literature are rather scarce but existing knowledge can be used to design a new study on the influence of RCA. Two time periods are critical for cracking of fresh and hardening concrete: an early period ranging from placing to $1-4 \mathrm{~h}$ and a late period that covers the setting time and early hardening. 
The phenomena that take place during the first critical time period are not specific of concrete mixtures. They can also characterize the drying of soils or other concentrated suspensions (Radocea 1994; Slowik et al. 2008). The water layer progressively disappears due to evaporation (Figure 8.1). Menisci are eventually formed between the particles at the sample surface. This results in the build-up of capillary pressure. As the curvature of menisci increases, the system of tensile forces between particles becomes unstable, and then, air starts to penetrate the pores. This finally causes local capillary pressure "breakthrough". The air entry concept is used to describe the phenomenon (Slowik et al. 2008). The air entry pressure is the capillary pressure at which the air is likely to penetrate the system. When the capillary pressure reaches a limit value called air entry value, air starts filling the largest pores and the capillary tension compresses the smaller pores and causes particle arrangement (Slowik and Ju 2011). From this time, the volume change is no longer equal to the loss of water, and the horizontal strains start to develop. Cracking was found to appear in the places where air entry pressure is reached; thus, air entry can be correlated with cracking (Souche et al. 2016).

Air entry depends on the composition of the material and its particle size distribution. In soil mechanics, the air entry value is usually determined from the volumetric water content versus suction curves. Other methods have been developed to determine the air entry for cement-based materials (Slowik et al. 2008; Souche et al. 2016).

RCA were found to influence the bleeding. A significant content of water is actually absorbed by such aggregates during mixing. Poon et al. reported that using RCA at the saturated surface-dried (SSD) state may result in bleeding during casting (Poon et al. 2004), at constant free water-to-cement $(\mathrm{W} / \mathrm{C})$ ratio of 0.57 .

The second critical time period covers the setting time and early hardening. When plastic shrinkage is restrained, tensile stresses develop. Cracking was found to occur when tensile stresses exceed the tensile strength (Ravina and Shalon 1968; Hammer et al. 2007). Moreover, the evolution of the tensile strain capacity shows a minimum at this time period. The significant increase in the modulus actually appears earlier than the significant increase in the tensile strength; thus, the strain capacity firstly decreases, and then, it increases with the tensile strength (Roziere et al. 2015).

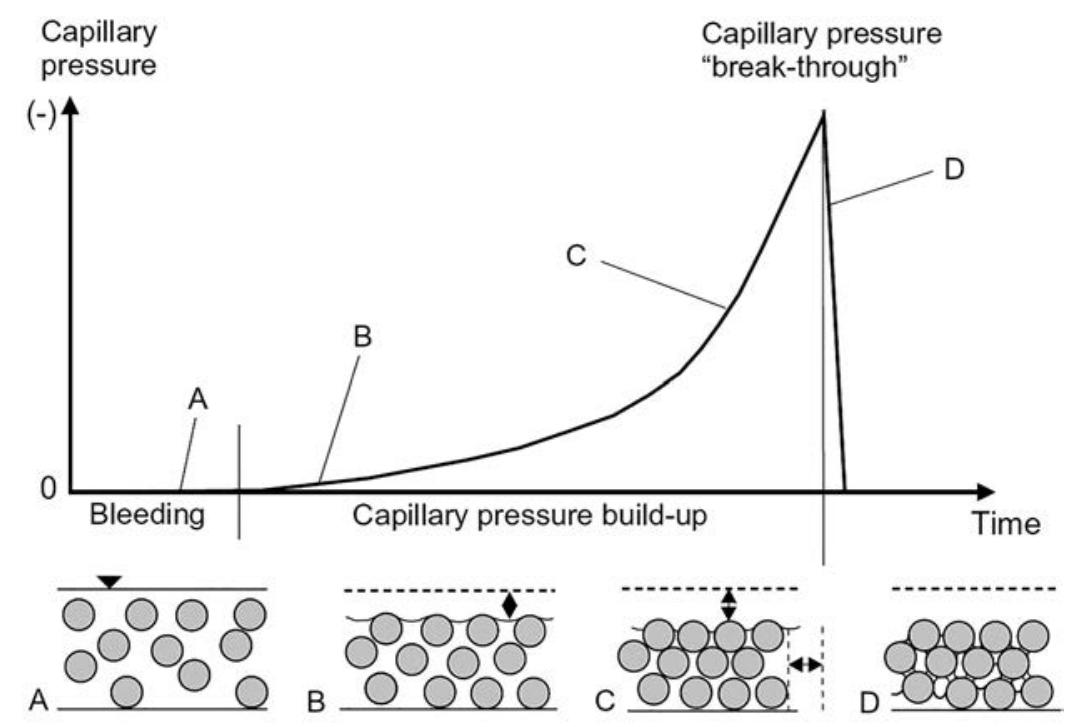

Figure 8.I Capillary pressure build-up in a drying suspension (Slowik et al. 2008). 


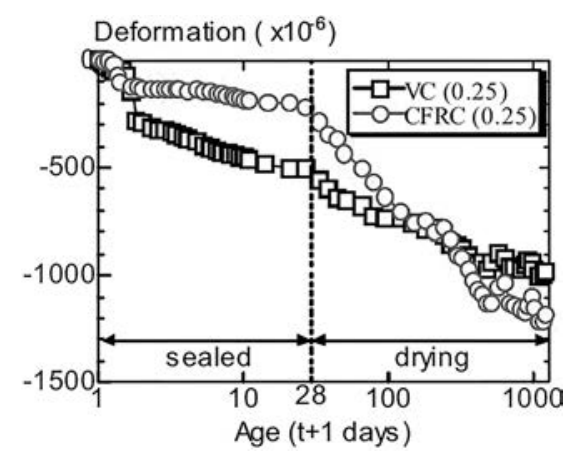

Figure 8.2 Deformation of high-strength concrete with virgin aggregate (VC) and high-strength concrete with recycled aggregate (CFRC), W/C $=0.25$ (Maruyama and Sato 2005).

RCA influences all the parameters involved in restrained shrinkage-induced cracking. On the one hand, increasing RCA proportions results in higher drying shrinkage (Figure 8.2) and sometimes in lower strength. Equivalent or higher strength can be reached through mix design. On the other hand, Young's modulus is reduced and creep increases. As a consequence, it is not easy to predict the influence of RCA on cracking sensitivity. Moreover, the initial water saturation of porous aggregates is likely to influence the plastic shrinkage and other concrete properties (Cortas et al. 2014). As shown in Figure 8.2, shrinkage was lower in sealed conditions (Maruyama and Sato 2005). Saturated recycled aggregates could actually mitigate autogenous shrinkage by water desorption mechanism, in a self-curing process. The water absorbed at setting time is influenced by the absorption kinetics of aggregates. If the aggregates are initially dry or partially saturated, the water remaining in cement paste at setting time is higher than the theoretical effective water content.

For example, Alhozaimy (2009) has shown that dry limestone aggregates did not fully absorb the part of added water required to compensate the absorption of aggregates, and thus, lead to an increase in the actual $\mathrm{W} / \mathrm{C}$ ratio of the mixes, increasing the initial slump and decreasing the compressive strength.

\subsection{RECYBÉTON'S OUTPUTS}

The water absorbed or released by porous aggregates is likely to influence the behavior of concrete at the early age, especially shrinkage-induced cracking. Thus, two experimental programs were designed to investigate the effects of RCA proportion and initial water saturation on plastic shrinkage (Figure 8.3). In program 1, the effect of external restraint on hardening concrete was studied under "standard" drying conditions characterized by low wind (Bendimerad 2016). Program 2 mainly dealt with the behavior of fresh concrete

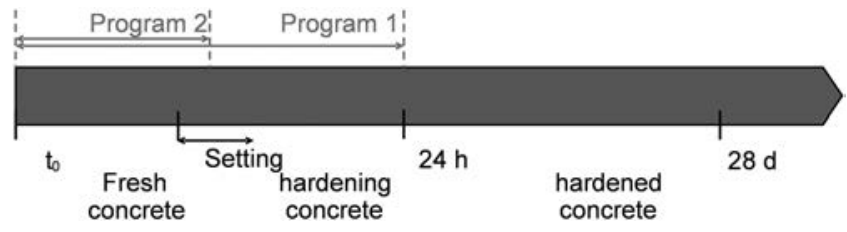

Figure 8.3 Main testing programs and stages of development of concrete properties ( $t_{0}$ first contact between water and cement). 
(Souche 2015). In order to promote the build-up of capillary pressure and cracking before setting, the wind speed was increased. This is referred to as "severe" drying conditions in the following sections.

\subsection{Experimental program}

\subsection{I.I Testing program}

Two series of concrete mixtures were studied (Sedran 2017): one for building applications called B and another for civil engineering applications called GC. They were designed with different total water/binder ratios (W/B) in order to reach $\mathrm{C} 25 / 30$ and $\mathrm{C} 35 / 45$ strength class.

The water absorption of aggregates is a key parameter in concrete mix design. Moreover, aggregates can be partially or totally saturated when they are introduced in concrete mixer. This initial water saturation of aggregates influences the early-age as well as the long-term behavior of concrete, even if the total water is kept constant (Cortas et al. 2014). The use of recycled aggregates in concrete actually modifies the available water at the different stages. To clarify these exchanges in water into fresh concrete, some notions are required.

First, the pre-saturation water $\left(W_{\mathrm{ps}}\right)$ corresponds to the amount of water in the aggregates before mixing. The additional water $\left(W_{\mathrm{ad}}\right)$ is the complementary water introduced in the mixer. The absorption water $\left(W_{\text {abs }}\right)$ is the water corresponding to saturated aggregates at nominal absorption, dried in surface (SSD state). The water remaining in the cement paste is called the free water $\left(W_{\mathrm{f}}\right)$. The total water $\left(W_{\text {tot }}\right)$ introduced in the mix is given by the following equation:

$$
W_{\mathrm{tot}}=W_{\mathrm{abs}}(A)+W_{\mathrm{f}}=W_{\mathrm{ps}}+W_{\mathrm{ad}}
$$

In the study presented in this chapter, considering that " $\mathrm{A}$ " is the initial water saturation of aggregates corresponding to the coefficient of water absorption measured at $24 \mathrm{~h}$ (EN 1097-6 2001), the 1.2A concretes have been made with aggregates at $120 \%$ SSD initial water saturation, which means a pre-saturation degree corresponding to the nominal absorption plus approximately $1 \%$ of dry mass of aggregates.

Two test programs have been conducted. The samples were tested under normal drying conditions, program 1 or under severe drying conditions, program 2, that is to say under wind (Table 8.1). In program 1, the free water content was kept constant. In program 2, added water was kept constant. For example, a building concrete (B) in program 1 with natural sand and recycled coarse aggregates pre-saturated at $1.2 \mathrm{~A}$ is named: $1 \mathrm{~B} 0 \mathrm{~S} 100 \mathrm{G}-$ 1.2A. All studied concretes are detailed in Table 8.2.

Table 8.I Exposure conditions

\begin{tabular}{|c|c|c|c|c|}
\hline & \multicolumn{2}{|c|}{ Program I } & \multicolumn{2}{|c|}{ Program 2} \\
\hline & \multicolumn{2}{|c|}{ Constant free water } & \multicolumn{2}{|c|}{ Constant added water } \\
\hline & \multicolumn{2}{|c|}{ Standard drying conditions } & \multicolumn{2}{|c|}{ Severe drying conditions } \\
\hline Concrete family & $B$ & GC & $B$ & GC \\
\hline $\mathrm{RH}(\%)$ & 50 & 50 & 45 & 45 \\
\hline Wind $(\mathrm{m} / \mathrm{s})$ & $<0.3$ & $<0.3$ & 8 & 8 \\
\hline
\end{tabular}




\begin{tabular}{lccccc}
\hline & & \multicolumn{4}{c}{ Substitution rate } \\
\cline { 3 - 6 } & & OSOG & OS30G & 30SOG & OSI00G \\
\hline Initial water & $0.3 \mathrm{~A}$ & - & - & - & I-BOSI00G_0.3A \\
saturation of RCA & $0.5 \mathrm{~A}$ & - & - & - & 2-BOSI00G_0.5A \\
& & & - & - & 2-GCOSI00G_0.5A \\
& $0.7 \mathrm{~A}$ & - & I-BOSI00G_0.7A \\
& IA & I-BOSOG_IA & I-BOS30G_IA & I-B30SOG_IA & I-BOSI00G_IA \\
& & I-GCOSOG_IA & & & I-GCOSI00G_IA \\
& I.2A & 2-BOSOG_I.2A & - & & I-BOSI00G_I.2A \\
& & 2-GCOSOG_I.2A & & & 2-BOSI00G_I.2A \\
& & & & & 2-GCOSI00G_I.2A \\
\hline
\end{tabular}

\subsubsection{Raw materials and concrete mixtures}

The recycled aggregates used in this study had a relatively high coefficient of water absorption of $8.9 \%$ for sand and from $5.6 \%$ to $5.8 \%$ for $4 / 10$ and $10 / 20$ fractions, respectively (Sedran 2013).

All the concrete mixtures were designed to reach C 25/30 and C 35/45 strength classes for building concretes (B) and civil engineering concretes (GC), respectively, with different proportions of fine or coarse RCA. They were made up of the same batch of Portland cement CEM II/A-L $42.5 \mathrm{~N}$ proceeding from the same cement plant. The cement had an estimated Bogue composition of $61 \% \mathrm{C}_{3} \mathrm{~S}, 0 \% \mathrm{C}_{2} \mathrm{~S}, 7.9 \% \mathrm{C}_{3} \mathrm{~A}, 12 \% \mathrm{C}_{4} \mathrm{AF}$, and $\mathrm{Na}_{2} \mathrm{Oeq}$ of $0.59 \%$, a Blaine fineness of $370 \mathrm{~m}^{2} / \mathrm{kg}$, and a density of $3.09 \mathrm{~kg} / \mathrm{m}^{3}$.

Limestone filler was taken into account into binder content (B), defined as the sum of cement and limestone filler contents (in $\mathrm{kg} / \mathrm{m}^{3}$ ).

The tested concrete mixtures were designed following the RECYBÉTON formulas (Sedran 2017) (Tables 8.3 and 8.4).

Table 8.3 Concrete mixtures tested in program I

\begin{tabular}{|c|c|c|c|c|c|c|}
\hline & \multicolumn{4}{|c|}{$I-B$} & \multicolumn{2}{|c|}{$I-G C$} \\
\hline & OSOG & $30 S O G$ & OS30G & OSIOOG & OSOG & OSIOOG \\
\hline NG 6,3/20 (kg/m $\left.{ }^{3}\right)$ & 820 & 829 & 462 & & 810 & \\
\hline RG I0/20 (kg/m $)$ & & & 296 & 701 & & 682 \\
\hline$N G 4 / 10\left(\mathrm{~kg} / \mathrm{m}^{3}\right)$ & 267 & 190 & 228 & & 264 & \\
\hline RG $4 / 10\left(\mathrm{~kg} / \mathrm{m}^{3}\right)$ & & & & 163 & & 158 \\
\hline NS $0 / 4\left(\mathrm{~kg} / \mathrm{m}^{3}\right)$ & 780 & 549 & 813 & 806 & 771 & 782 \\
\hline RS 0/4 $\left(\mathrm{kg} / \mathrm{m}^{3}\right)$ & & 235 & & & & \\
\hline Cement, $C\left(\mathrm{~kg} / \mathrm{m}^{3}\right)$ & 270 & 276 & 276 & 282 & 299 & 336 \\
\hline Limestone, $L\left(\mathrm{~kg} / \mathrm{m}^{3}\right)$ & 45 & 31 & 31 & 31 & 58 & 53 \\
\hline Superplasticizer SP $\left(\mathrm{kg} / \mathrm{m}^{3}\right)$ & 0.747 & 0.798 & $0.86 I$ & 0.798 & 1.26 & 1.31 \\
\hline$W_{f}\left(\mathrm{~kg} / \mathrm{m}^{3}\right)$ & 180 & 185 & 185 & 189 & 175 & 185 \\
\hline$W_{\text {tot }}\left(\mathrm{kg} / \mathrm{m}^{3}\right)$ & 194.6 & 221.4 & 212.3 & 241 & 188.7 & 235.1 \\
\hline$W_{f} / B\left(k g / m^{3}\right)$ & 0.57 & 0.60 & 0.60 & 0.60 & 0.49 & 0.48 \\
\hline Volume of paste $\left(\mathrm{L} / \mathrm{m}^{3}\right)$ & 285 & 287 & 287 & 293 & 302 & 321 \\
\hline Packing density $\mathrm{g}^{*}$ & 0.785 & 0.79 & $0.78 I$ & 0.777 & 0.784 & 0.772 \\
\hline MPT (mm) & 0.80 & 0.86 & 0.82 & 0.89 & 0.90 & 1.05 \\
\hline
\end{tabular}


Table 8.4 Concrete mixtures tested in program 2

\begin{tabular}{|c|c|c|c|c|c|c|}
\hline & \multicolumn{3}{|c|}{$2-B$} & \multicolumn{3}{|c|}{$2-G C$} \\
\hline & OSOG & $0 S 100 G-1.2 A$ & OSI00G-0.5A & OSOG & $0 S 100 G-1.2 A$ & OSI00G-0.5A \\
\hline NG 6,3/20 (kg/m $\left.{ }^{3}\right)$ & 820 & & & 810 & & \\
\hline RG I0/20 (kg/m $\left.{ }^{3}\right)$ & & 701 & 701 & & 682 & 682 \\
\hline NG $4 / 10\left(\mathrm{~kg} / \mathrm{m}^{3}\right)$ & 266 & & & 264 & & \\
\hline RG $4 / 10\left(\mathrm{~kg} / \mathrm{m}^{3}\right)$ & & 163 & 163 & & 158 & 158 \\
\hline NS 0/4 $\left(\mathrm{kg} / \mathrm{m}^{3}\right)$ & 780 & 806 & 806 & 771 & 782 & 782 \\
\hline \multicolumn{7}{|l|}{$\operatorname{RS} 0 / 4\left(\mathrm{~kg} / \mathrm{m}^{3}\right)$} \\
\hline Cement, $C\left(\mathrm{~kg} / \mathrm{m}^{3}\right)$ & 270 & 282 & 282 & 299 & 336 & 336 \\
\hline Limestone, $L\left(\mathrm{~kg} / \mathrm{m}^{3}\right)$ & 45 & 31 & 31 & 58 & 53 & 53 \\
\hline Superplasticizer SP $\left(\mathrm{kg} / \mathrm{m}^{3}\right)$ & 1.35 & 1.40 & 1.40 & 2.10 & 2.18 & 2.18 \\
\hline$W_{f}\left(\mathrm{~kg} / \mathrm{m}^{3}\right)$ & 166 & 174 & 149.1 & 151 & 157 & 133 \\
\hline$W_{\text {tot }}\left(\mathrm{kg} / \mathrm{m}^{3}\right)$ & 180 & 232 & 207 & 165 & 213 & 189 \\
\hline$W_{\mathrm{f}} / B\left(\mathrm{~kg} / \mathrm{m}^{3}\right)$ & 0.53 & 0.56 & 0.48 & 0.42 & 0.40 & 0.34 \\
\hline Vol. of paste $\left(\mathrm{L} / \mathrm{m}^{3}\right)$ & 289 & 292 & 282 & 292 & 304 & 293 \\
\hline Packing density $\mathrm{g}^{*}$ & 0.785 & 0.777 & 0.777 & 0.784 & 0.772 & 0.772 \\
\hline
\end{tabular}

\subsection{I.3 Testing procedures}

The testing procedures used in programs 1 and 2 are, respectively, described in GeM (Turcry 2004; Bendimerad 2016; Mbemba 2010; Souche 2015). The tests started $20 \mathrm{~min}$ after the first contact between water and cement. For all curves, the origin of time is the beginning of drying.

\subsubsection{Behavior of fresh concrete before setting}

\subsubsection{Effect of environmental conditions on recycled concrete behavior}

The plastic shrinkage evolution plotted as a function of weight loss (Figure 8.4) shows similar trends of samples in both drying conditions. The development of plastic shrinkage was slightly delayed for concretes of program 2 . They actually showed higher bleeding (independently from drying conditions) than concretes tested in program 1 . Then, the second phase showed a constant shrinkage rate.

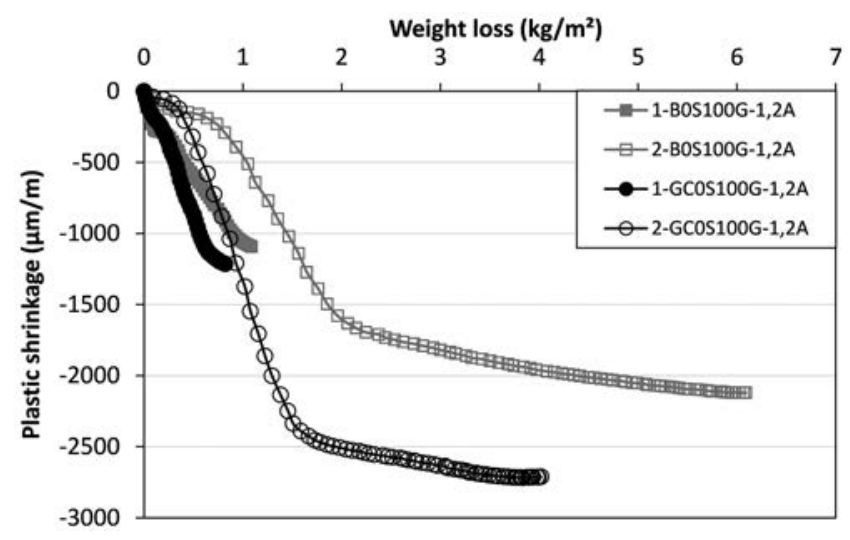

Figure 8.4 Plastic shrinkage versus weight loss. 
The slope of the linear part of the curves was identical in both programs, for a given concrete mixture. Finally, during the third phase, the shrinkage rate gradually decreased until the end of the test, and the weight losses resulted in increasing air content in the pore system. The beginning of the third phase appeared at lower weight loss for concretes of program 1 . In standard drying conditions, the decrease in plastic shrinkage rate actually occurred between the initial and final setting times, when shear modulus became significant (Bendimerad et al. 2016). In severe conditions, plastic shrinkage mostly developed before $2 \mathrm{~h}$. At this age, the stiffness of concrete was still negligible; thus, the development of plastic shrinkage was not limited, and it reached higher values. The increase in drying rate had a stronger influence on the plastic shrinkage of civil engineering concretes, characterized by lower initial $W / B$ ratio.

\subsubsection{Effect of substitution rate and initial water saturation of $R C A$}

The water content of recycled aggregates was measured at different ages under sealed and drying conditions. The purpose of these tests is to evaluate hydric transfers between recycled aggregates and cement paste over time with and without drying. The experimental protocol is inspired by Bello's work (Bello 2014) on lightweight aggregates and is described in Figure 8.5.

After mixing, concrete is stored under endogenous or desiccated conditions. Approximately every $10 \mathrm{~min}$, a sample of fresh concrete is sieved through a $5-\mathrm{mm}$ sieve in order to separate cement paste and coarse recycled aggregates. The wet aggregates are weighed and dried in an oven for $2 \mathrm{~h}$. Once aggregates are dried, they are weighed again (Salgues et al. 2016).

Results are given in Figure 8.6 for 2-B0S100G-0.5A concrete. The purpose of these tests was to evaluate hydric transfers between recycled aggregates and cement paste over time with and without drying (Salgues et al. 2016). The behavior of recycled aggregates depends

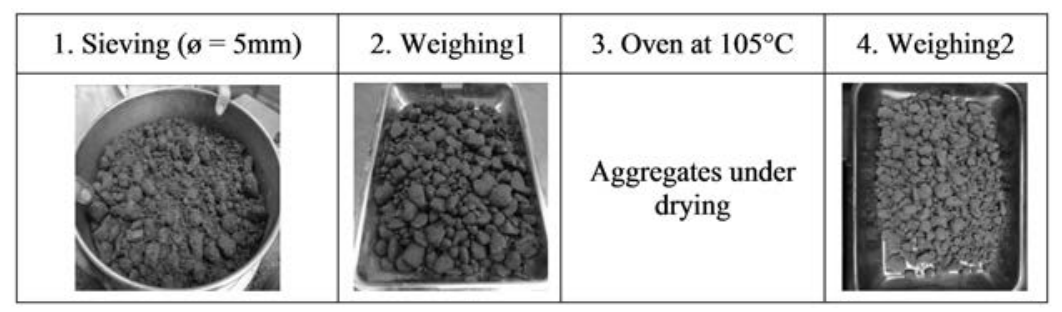

Figure 8.5 Test protocol to measure water in coarse recycled aggregates during time (Salgues et al. 2016).

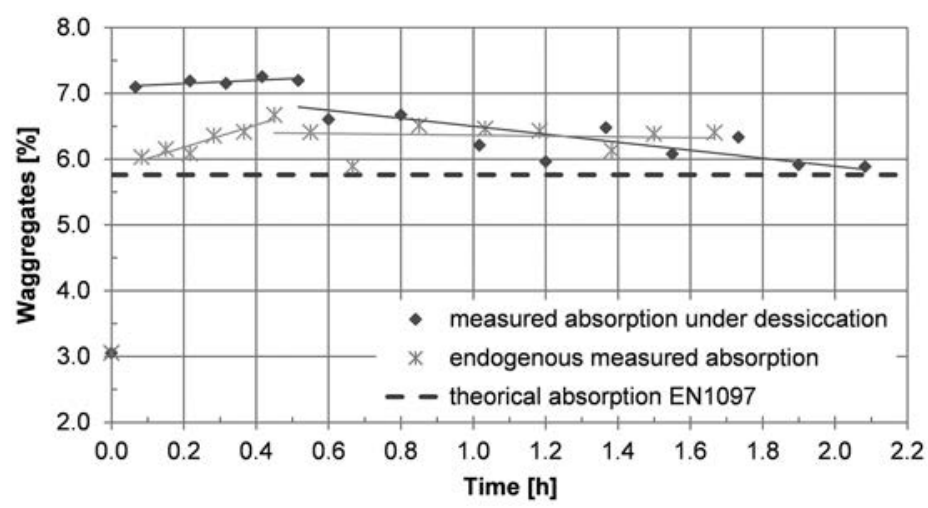

Figure 8.6 Water content of recycled aggregates ( $\mathrm{g}$ of water/g of dry aggregates) in concrete 2-BOSI00G$0.5 \mathrm{~A}$ under drying and endogenous conditions (Salgues et al. 2016). 
on their initial saturation state. Initially, unsaturated aggregates absorb water while being mixed to nearly reach its maximum absorption, as shown in Figure 8.6.

Slight water absorption can occur up to 30 minutes after pouring fresh concrete. Therefore, the water absorption of the recycled aggregates in the cement paste is very fast, and the result is in accordance with the absorption of recycled aggregates in the water (De Brito et al. 2011; Bendimerad et al. 2015). Nevertheless, after this first absorption phase, under severe wind conditions, aggregates from 2-B0S100G-0.5A release water due to the lack of water in concrete and paste. Endogenous conditions for B0S100G-0.5A concrete do not highlight this water transfer (Figure 8.6).

According to these first results, it is interesting to monitor the variation in the volume of water in the aggregates, cement paste, and concrete. The different phases are shown in Figure 8.7. In the mixer, the unsaturated recycled aggregates complete their absorption until $90 \%$ of the nominal value. Then, the absorption can continue after casting during the first half of an hour. After casting, as soon as the desiccation begins, the concrete homogeneously loses water. This water is provided by aggregates and/or cement paste.

Figure 8.8 shows the plastic shrinkage value at $7.2 \mathrm{~h}$ as a function of $W / B$ ratio between total water and binder. Under standard conditions, the plastic shrinkage magnitude decreased with an increase in $W / B$ ratio, whereas it increased under severe conditions.
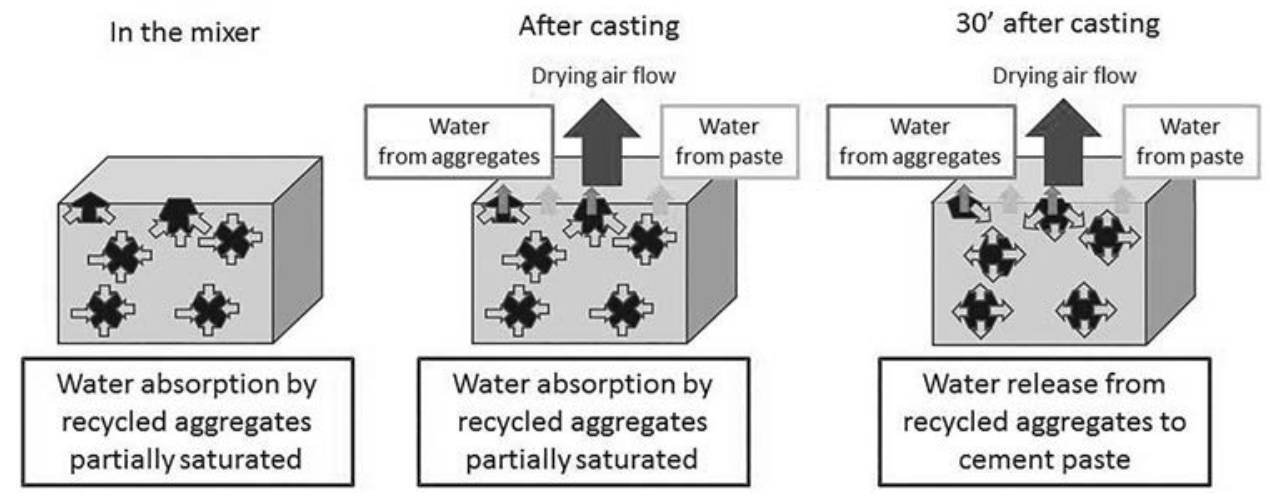

Figure 8.7 Hydric transfers in concrete, cement paste, and recycled aggregates over time for B0SI00G-0.5A concrete (Salgues et al. 2016).

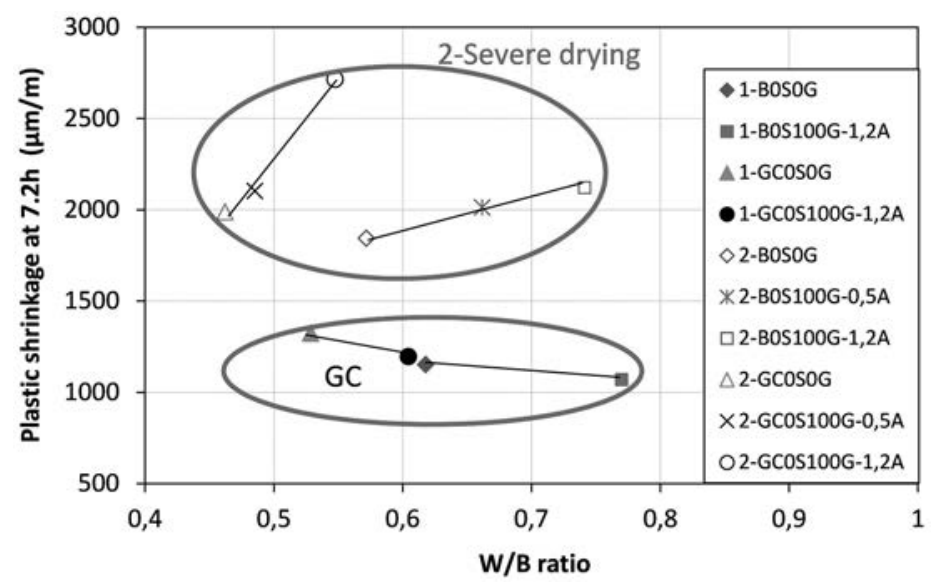

Figure 8.8 Plastic shrinkage at $7.2 \mathrm{~h}$ versus $W / B$ ratios (total $W / B$ ratio). 
The increase in $W / B$ ratio generally favors bleeding, which delays and mitigates the development of plastic shrinkage. Severe conditions did not result in higher plastic shrinkageto-weight loss ratios, but they significantly influenced the magnitude of plastic shrinkage. At high evaporation rates, the development of plastic shrinkage was accelerated, and thus, it could develop before the initial setting time, which was not possible in standard drying conditions (Figure 8.4).

For building concretes under severe drying conditions, the shrinkage versus $W / B$ ratio can be plotted as a linear function (Figure 8.8). For civil engineering concretes, another linear function was found, with a higher slope. These correlations could be explained by the influence of mix design and the behavior of RCA. RCA concrete mixtures actually had higher paste proportions (Table 8.4), and shrinkage magnitude increases linearly with paste volume (Hansen and Almudaiheem 1987). Moreover, severe drying is likely to cause drying of RCA (Maruyama and Sato 2005; Wyrzykowski et al. 2015), whereas they can provide internal curing in sealed conditions or standard drying conditions. Finally, increasing RCA proportion results in an increase in drying shrinkage of concrete because of their original paste content and lower modulus.

Finally, the influence of RCA on plastic shrinkage depends on drying conditions. In severe conditions, it resulted in an increase in shrinkage, whereas it mitigated shrinkage development in standard drying conditions.

\subsubsection{Cracking sensitivity under severe drying conditions}

In this part, a fine drained soil model was used to determine the air entry value. Firstly, it is necessary to build the fresh concrete characteristics curves. The concrete characteristics curves are defined as the relationship between water content (\%) and capillary pressure $(\mathrm{hPa})$ in a semi-log description. According to the method developed for fine soils, the air entry value can be approximated as the point at which the two lines intersect (Souche 2015; Souche et al. 2016).

Figure 8.9 shows that the air entry value is highly dependent on effective $W / B$ ratio $\left(W_{\mathrm{f}} / B\right)$. Binder content takes into account all the cements and all the calcareous fillers. Coarse RCA

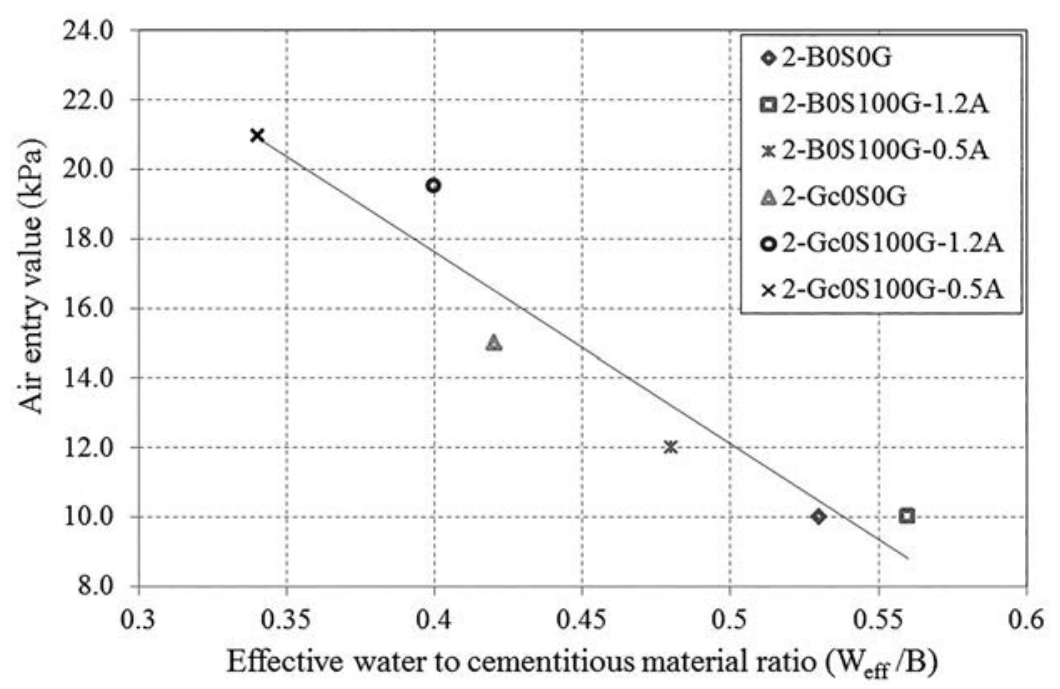

Figure 8.9 Influence of $W_{f} / B$ ratio on air entry value (Souche et al. 2016). 


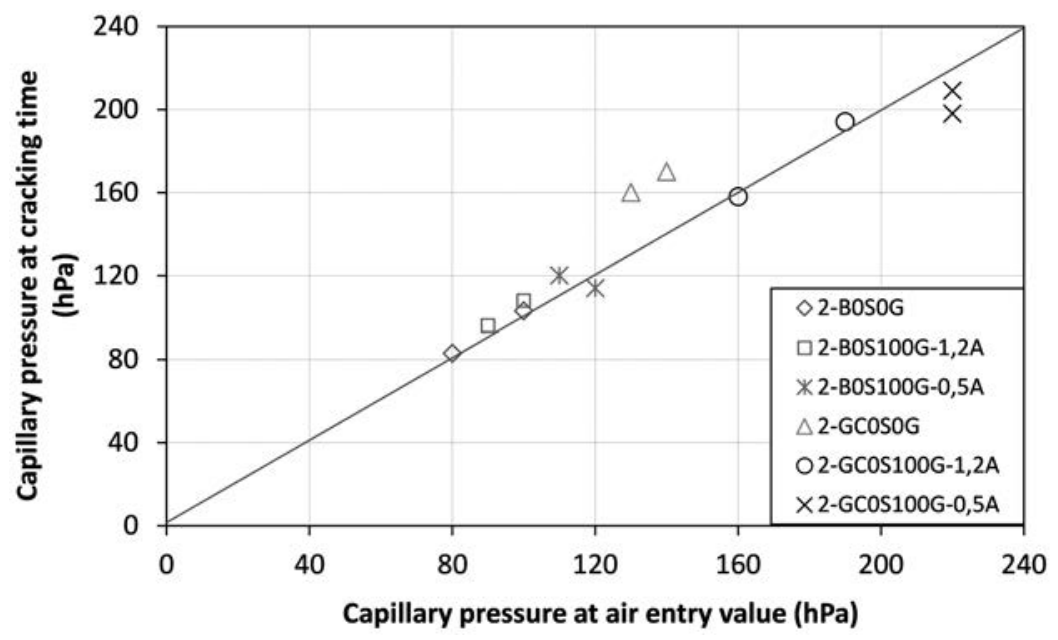

Figure 8.10 Capillary pressure at cracking time as a function of air entry values (Souche 2015).

do not seem to influence the air entry value as the air entry value is a physical characteristic of the paste. Then, the field of capillary depressions is disturbed by the air entry, and the identification of permeability coefficient starting from the capillary depression gradient is not possible anymore. After the air entry, fresh concrete becomes an unsaturated porous medium.

For each concrete, capillary pressure at cracking time can be compared to air entry value. Figure 8.10 represents the measured capillary pressure values at cracking time as a function of the calculated air entry value for all concretes. For conventional concrete (NC) and recycled concrete (RC), Figure 8.10 brings to light a strong linear correlation between air entry value and cracking pressure.

Cracking occurs around the air entry. For NC, it confirms the results from previous studies (Slowik et al. 2008; Slowik and Ju 2011): air entry is a critical period for cracking of fresh concrete. For RC, the same behavior as NC is observed. The local overstresses cause cracking. According to the pre-saturation degree, the unsaturated RCA complete their absorption modifying the effective water of the paste. On the opposite, the initially oversaturated RCA could provide a potential internal curing to the paste under desiccation. So according to Salgues et al. (2016), the water contained into RCA had a direct impact on concrete cracking time at the early age.

\subsubsection{Behavior of hardening concrete}

\subsubsection{Effect of substitution rate}

The graphs (Figure 8.11) showed the influence of the percentage of substitution of natural aggregates by coarse or fine RCA on 24-h plastic shrinkage magnitude (Turcry and Loukili 2006).

In this study, all the curves were initialized at the age of initial deformation defined in Bendimerad et al. (2016), when the temperature of fresh concrete first reaches the temperature of the mold (around $1 \mathrm{~h}$ ). B0S30G and B0S100G concretes showed nearly the same plastic shrinkage magnitude, close to $1,100 \mu \mathrm{m} / \mathrm{m}$. When they are compared to the $\mathrm{NC}$, the difference is significant but lower than $10 \%$. This can be explained by the maximal paste thickness (MPT) concept (de Larrard and Sedran 1994; de Larrard and Belloc 1997). Considering that the aggregates mix is filled with cement paste, the MPT actually represents 


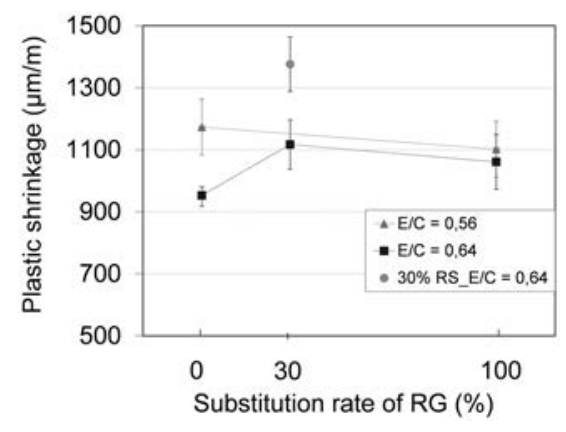

Figure 8.II Effect of substitution rate on plastic shrinkage.

the paste that is in free shrinkage configuration. The values of the MPT of the three concrete mixtures were actually very close (Figure 8.12). The most significant plastic shrinkage concerned concrete with recycled sand. Because of the higher surface area of fine RCA, the bleeding water is lower than in the control mix, and the risk of plastic shrinkage related to insufficient curing increases.

This study aimed at providing data to understand the evolution of the shrinkage-induced cracking sensitivity of different conventional and RCs at the early age. The concrete tensile strength was experimentally assessed $24 \mathrm{~h}$ after casting using the direct tensile test. The percentage of substitution of recycled gravel or sand significantly affected the mechanical properties, such as elastic modulus and tensile strength (Figure 8.13).

\subsubsection{Effect of initial water saturation}

The plastic shrinkage measurements on the B0S100G concrete with different initial water saturation of gravel showed minor differences. The magnitude at $24 \mathrm{~h}$ was between 870 and $1,055 \mu \mathrm{m} / \mathrm{m}$ (Figure $8.14 \mathrm{a}$ ). The initial setting times were around $6 \mathrm{~h}$, and the final setting times were around $11 \mathrm{~h}$. From the final setting to $24 \mathrm{~h}$, shrinkage did not significantly increase.

The mixtures with initial saturation 1B0S100G-0.3A and 1B0S100G-1.2A showed the lowest values. The concrete with $0.3 \mathrm{~A}$ had the highest added water $\left(W_{\text {add }}=218.4 \mathrm{~kg} / \mathrm{m}^{3}, W_{\text {aggr. }}=\right.$ $22.6 \mathrm{~kg} / \mathrm{m}^{3}$ ), which implies a higher bleeding rate (Almusallam et al. 1998). This additional

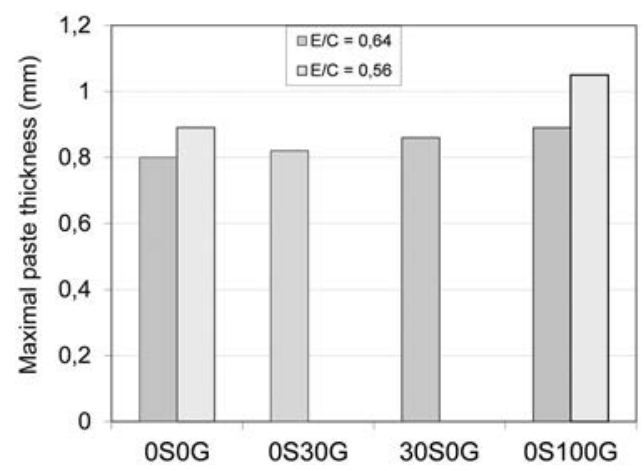

Figure 8.12 Effect of substitution rate on MPT. 


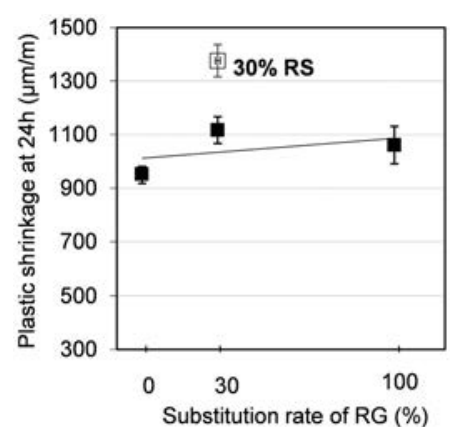

(a)

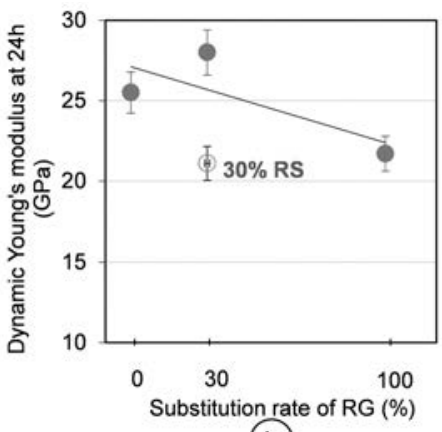

(b)

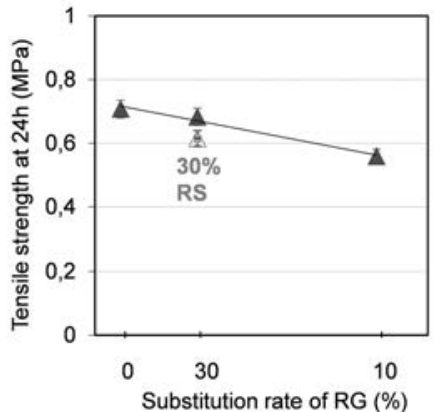

(c)

Figure 8.13 Influence of substitution rate of RCA on early-age properties: Plastic shrinkage (a), Young's modulus (b), Tensile strength (c).

(a)

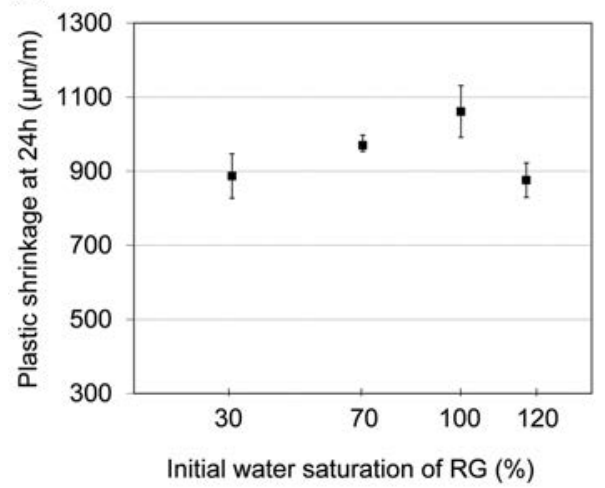

(b)

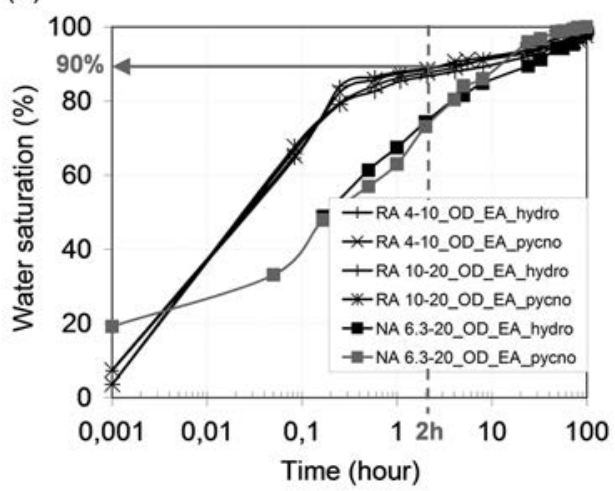

Figure 8.14 Correlation between plastic shrinkage and rate of water absorption. (a) Effect of water saturation of recycled aggregate concrete on plastic shrinkage; (b) influence of aggregate type on water absorption rate (Bendimerad et al. 2015).

bleeding water mitigated the plastic shrinkage of concrete at $0.3 \mathrm{~A}$. The concrete with oversaturated gravel $(1.2 \mathrm{~A})$ had a relatively low shrinkage as well. This mixture $1.2 \mathrm{~A}$ ( $W_{\text {add }}=$ $\left.179.8 \mathrm{~kg} / \mathrm{m}^{3}, W_{\text {aggr. }}=61.2 \mathrm{~kg} / \mathrm{m}^{3}\right)$ was characterized by the same total water as $0.3 \mathrm{~A}$ concrete. Oversaturated gravel actually releases water in cement paste and provides self-curing in concrete (Zhutovsky et al. 2002). This internal curing was also observed in the case of RC (Salgues et al. 2016).

Absorption measurements on different aggregates showed a relatively high water saturation rate of recycled aggregates during the first hour (Bendimerad et al. 2015). After $2 \mathrm{~h}$, the water saturation actually reached $90 \%$ (Figure $8.14 \mathrm{~b}$ ). Therefore, when the development of plastic deformation begins, the major part of water saturation has already occurred, which explains the limited effect of initial water saturation.

The values of mechanical properties (elastic modulus and tensile strength) at $24 \mathrm{~h}$ show that the effect of initial water saturation of coarse aggregates was negligible (Figure 8.15). 


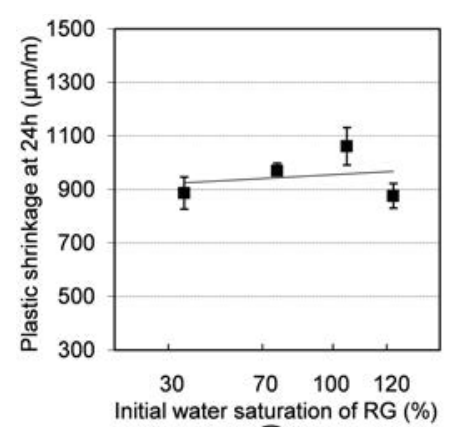

(a)

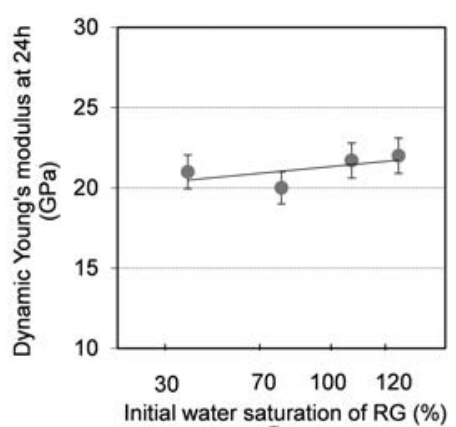

(b)

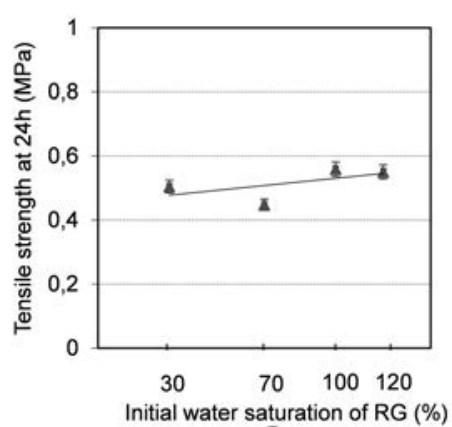

(c)

Figure 8.15 Influence of initial water saturation of RCA on early-age properties of concrete I-BOSI00G (Bendimerad et al. 2016).

\subsection{RESEARCH NEEDS}

Few studies deal with the influence of RCA on early-age behavior of concrete. A comprehensive study involving two laboratories has been designed to understand the influence of initial water saturation and RCA proportion on water movements in fresh concrete and properties of hardening concrete. This study presented in this chapter mainly dealt with coarse aggregates. This material was characterized by relatively high purity, low original paste content, and high absorption rate. The results obtained with fine RCA (sand) were totally different, which underlines the need to take into account the properties of RCA. Further research would include experimental studies on the influence of RCA purity and fine RCA proportions. Although their proportion in RCA is low, the fines (powder produced by crushing original concrete) have a significant influence on plastic shrinkage because of high water absorption.

In terms of testing and analyses, the investigation on the cracking sensitivity lacks the assessment of tensile creep or relaxation at the early age. These properties cannot be easily determined by direct testing. However, restrained shrinkage tests allow an indirect estimation. For instance, temperature stress testing machine system provides the evolution of free and restrained deformations, from which creep and relaxation can be deduced (Bendimerad 2016).

RCA influence the early-age behavior of concrete at different levels, and the effects are often coupled. As a consequence, experimental studies do not always allow separating the effects due to RCA intrinsic properties and their behavior in cement paste. Thus, multiscale modeling appears as a promising approach to understand these complex phenomena.

\subsection{CONCLUSIONS}

Two experimental programs were connected to provide data on the influence of RCA proportion and initial water saturation on plastic shrinkage, cracking risk, and concrete properties at the early age. Several conclusions can be drawn from this comprehensive study.

- Due to the relatively high porosity, RCA absorb water that can be released in cement paste. In sealed conditions or under moderate drying conditions, this provides internal curing that mitigates plastic shrinkage. However, under severe conditions, high evaporation rates are likely to trigger the drying of aggregates, which results in an increase in shrinkage magnitude. 
- Air entry concept can be used to investigate the influence of RCA on cracking risk of fresh concrete. Cracking time was assessed through specific testing (ASTM C1579), and experimental results actually showed a strong correlation with air entry determined from water content versus capillary pressure curves of the studied concretes.

- The coarse RCA used in this study had high absorption rate; thus, the water content remaining in the cement paste was close to the theoretical free water content. A relatively low influence of initial water saturation was actually observed when keeping the total water constant. At the variable total water contents, the air entry pressure linearly decreased with free $W / B$ ratio $\left(W_{\mathrm{f}} / B\right)$, whatever the type of aggregates.

- The proportion of RCA had a significant influence on properties of concrete: plastic shrinkage, Young's modulus, and tensile strength. However, it is not possible to conclude on cracking sensitivity from these results, as the influence of RCA on relaxation has not been assessed in this study.

From the experimental results, careful curing of RCA concretes can be recommended. The studies actually show a strong coupling between initial water saturation, properties of fresh concrete, and drying exposure on plastic shrinkage and cracking risk. RCA proportion and initial saturation do not induce higher cracking sensitivity in themselves, but they are likely to promote cracking in severe drying conditions (initially dry RCA and high evaporation rate).

\section{ACKNOWLEDGMENTS}

Support from the Agence Nationale de la Recherche (National Research Agency, France) within ECOREB project and Project national (National Project, France) RECYBÉTON is gratefully acknowledged. 